\title{
Teatro e Ocupação: possíveis diálogos com as práticas de Teatro e Comunidade
}

Caroline da Silva Barbosa ${ }^{1}$

Recebido em: 15/04/2020

Aprovado em: 14/05/2020

DOI: $10.5965 / 2358092521232020121$

1 Mestranda em Artes Cênicas pela Universidade Federal do Estado do Rio de Janeiro (UNIRIO). Professora de Artes Cênicas na Secretaria Municipal de Educação do Rio de Janeiro (SME/RJ). E-mail: carolbarbosa.0803@gmail.com 


\section{RESUMO}

O presente trabalho aponta possíveis diálogos entre o campo de pesquisa Teatro e Comunidade e as ocupações secundaristas que ocorreram durante o primeiro semestre de 2016 na Rede Estadual de Ensino do Rio de Janeiro. Dentro dos espaços ocupados foi possível perceber que os estudantes ressignificaram a ideia de escola construindo práticas cotidianas a partir de seus próprios interesses. Nesse momento, o teatro passou a ser um aliado e muitos professores, artistas e simpatizantes das artes foram convidados pelos estudantes para propor encontros teatrais, como oficinas e apresentações de seus espetáculos. Perguntei-me qual pedagogia teatral um professor poderia propor dentro de um contexto tão específico para contribuir de alguma maneira com a luta dos estudantes. Encontrei como caminho os estudos de Augusto Boal, Paulo Freire e pesquisadores do Teatro e Comunidade, que nortearam tanto as práticas teatrais desenvolvidas dentro das ocupações que pude visitar quanto a elaboração deste artigo.

Palavras-chave: Pedagogia do teatro, teatro e comunidade, ocupações.

\section{ABSTRACT}

This study seeks to point out possible connections between the Theater and Community field research and high schools occupations that occurred during the first semester of 2016 inside Rio de Janeiro's public schools. Within the occupied spaces, it was possible to notice that the students reinterpreted the idea of school creating new daily practices based on their own interests. At that moment, the theater became an ally and many teachers, artists and supporters of the arts were invited by the students to organize theatrical meetings, such as workshops and presentations of their shows. I 
wondered which theatrical pedagogy could a teacher propose within such a specific context to somehow contribute to the student's struggle. As an answer, I found the studies of Augusto Boal, Paulo Freire and Theater and Community researchers, which guided both my theatrical practices developed within the occupations that I was able to visit and the elaboration of this article.

Keywords: Theatre pedagogy, theater and community, occupations.

\section{INTRODUÇÃO}

O presente artigo tem como ponto de partida as ocupações dos Colégios Estaduais do Rio de Janeiro no primeiro semestre de 2016. Em abril do mesmo ano, fui convidada a dar uma oficina de teatro dentro da primeira escola ocupada na cidade de Angra dos Reis, o Centro Integrado de Educação Pública, CIEP, 302 Charles Dickens e, a partir de então, pude me aproximar daquela nova realidade dentro do espaço escolar. Naquela ocasião, chamou-me atenção a forma como os estudantes estavam se organizando e pude perceber que dentro da programação pensada por eles havia uma quantidade considerável de atividades artísticas: oficina de teatro e hip-hop, cine debate, produção de curta-metragem, sarau. Tendo acesso a informações de mais escolas, como os Colégios Estaduais Salim Miguel e Stuart Edgar Angel Jones, seja por visitas presenciais, pelas páginas do Facebook, ou pelos relatos dos estudantes angrenses que se comunicavam com outros secundaristas do Rio de Janeiro através das redes sociais, percebi que essas práticas eram semelhantes em todo o Estado. Surgiu, então, a primeira pergunta da pesquisa: de que forma as linguagens artísticas poderiam dialogar com a luta dos estudantes secundaristas?

Dentro do contexto ressignificado da escola, ao pensar de que forma poderia planejar um encontro dos estudantes comigo por meio do teatro - naquele momento, não como professora de Artes, que seguia um currículo específico dentro da Rede 
Estadual, mas como uma pessoa que estava ali para experimentar com os estudantes essa linguagem a partir das demandas deles - lembrei da experiência que tive por quatro anos dentro do Programa de Extensão Teatro em Comunidades ${ }^{2}$ durante a graduação em Licenciatura em Teatro na Universidade Federal do Estado do Rio de Janeiro, UNIRIO. Nesse projeto, os encontros eram pensados a partir da troca com os jovens da Maré e as principais bases dos nossos planejamentos eram os estudos de Paulo Freire e Augusto Boal, que são, segundo a Profa. Dra . Márcia Pompeo Nogueira (in memoriam), pesquisadora do campo Teatro e Comunidade ${ }^{3}$, os principais suportes metodológicos dos trabalhos desenvolvidos nessa área tanto no Brasil quanto no mundo. Nesse sentido, a segunda pergunta da pesquisa é: 0 espaço escolar ressignificado é um possível lugar de diálogo com as bases do Teatro e Comunidade?

Em 2017, ao ingressar no Programa de Pós-Graduação em Artes Cênicas da UNIRIO, comecei a estruturar os meus estudos sobre o tema tendo dois pontos de partida: a pesquisa de campo, que tem como uma de suas ferramentas as entrevistas

20 Programa foi criado em 2011 na Universidade Federal do Estado do Rio de Janeiro - UNIRIO, pela profa. Dra. Marina Henriques Coutinho. Visa a promover a produção de conhecimento em teatro, a prática artística e pedagógica, estimulada pelo encontro entre os estudantes da Escola de Teatro da UNIRIO e jovens moradores do Complexo da Maré, maior complexo de favelas da cidade do Rio de Janeiro.

3 É necessário ressaltar que a nomenclatura destinada ao campo de estudo Teatro e Comunidade varia em todo o mundo. Segundo a Profa. Dra. Marina Henriques Coutinho, "na Inglaterra, por exemplo, a literatura dedicada à área também acolhe diversos termos e 'modalidades teatrais', tais como: performance comunitária, teatro para mudança social, teatro popular, teatro de intervenção, teatro para o desenvolvimento, teatro comunidade e teatro para a solução de conflitos. Embora cada uma delas apresente formulações teóricas específicas, não é difícil identificar entre elas características comuns: [...] envolvem a participação de pessoas comuns, suas histórias, lugares, desejos, prioridades e que são motivadas pelo desejo político de transformar, por meio do teatro, realidades individuais e coletivas" (COUTINHO, 2012, p. 89). 
semiestruturadas ${ }^{4}$, as quais foram inicialmente feitas com os estudantes secundaristas de Angra dos Reis ${ }^{5}$; e a pesquisa bibliográfica, que se deu baseada em estudos recentes sobre os campos teatro político, ocupação estudantil e pedagogia do teatro.

Tendo como base esses pontos presentes em minha pesquisa, este breve artigo, portanto, objetiva, refletir a respeito das práticas teatrais desenvolvidas em espaços onde as relações pretendem ser horizontais, dialógicas, estruturadas coletivamente no afeto e na esperança de um mundo mais justo, nomeado pelos sujeitos que nele estão inseridos. Intenta-se também conectar as práticas ocorridas no espaço concreto das ocupações estudantis com as metodologias que embasam o campo Teatro e Comunidade.

\section{AS OCUPAÇÕES ESTUDANTIS}

A quem pertence a escola pública no Brasil? Em 2016, durante a greve dos professores da Rede Estadual do Rio de Janeiro, os estudantes secundaristas decidiram ocupar as escolas para reivindicar alguns pontos de suas pautas de luta, como mais tempos de Sociologia e Filosofia na grade curricular do Ensino Médio, eleição ${ }^{6}$ para diretores, fim do Sistema de Ava-

4 "As entrevistas semiestruturadas combinam perguntas abertas e fechadas, onde o informante tem a possibilidade de discorrer sobre o tema proposto. O pesquisador deve seguir um conjunto de questões previamente definidas, mas ele o faz em um contexto muito semelhante ao de uma conversa informal" (QUARESMA; BONI, 2004, p. 75).

5 Dividi a pesquisa em três partes. Na fase inicial entrevistei os primeiros estudantes secundaristas com quem tive contato mais próximo na cidade de Angra dos Reis, onde fui professora de Artes pela Rede Estadual de Ensino antes do período das ocupações e durante ele. Na segunda fase, entrevistei duas professoras de teatro que deram oficinas em diferentes ocupações de escolas do estado. Na última fase, novamente encontrei com estudantes secundaristas que tiveram acesso às oficinas dessas professoras. A proposta, nesse sentido, foi partir da minha própria experiência e relacioná-la com outras em outros espaços.

$6 \mathrm{Na}$ maioria das escolas as direções eram compostas por indicação. A obrigatoriedade das eleições permitiu modificar esse cenário. BARREIRA, Gabriel. RJ san- 
liação da Educação do Estado do Rio de Janeiro, SAERJ7, melhor infraestrutura nas escolas, dentre outras propostas específicas em cada espaço escolar. Essas mobilizações não eram um acaso, segundo os pesquisadores Angelina Rojas, Marcelo Mocarzel e Mary Rangel (2017). Para eles, as ocupações do Rio de Janeiro fizeram parte de um movimento maior e teriam se inspirado nas ocupações das escolas estaduais de São Paulo em 2015, que surgiram como resposta a uma "reorganização" escolar proposta pelo governador Geraldo Alckmin. Essas mobilizações, por sua vez, tiveram como uma de suas inspirações a revolta dos estudantes do Chile em $2006^{8}$.

É importante lembrar que a socialização escolar cumpre um papel importante, como foi observado por Pierre Bourdieu (2007). O autor aponta como a escola, ao afirmar valores e pensamentos típicos do habitus ${ }^{9}$ das classes dominantes, constrói um conjunto de práticas e ideologias tido como legítimo que serve de ferramenta para um processo de marginalização e silenciamento dos oprimidos. Além disso, a estrutura formal da escola está, muitas vezes, baseada no que Paulo Freire $(2013)$ chama de educação bancária, por meio da qual o educador, em vez de comunicar-se, decide depositar as ideias nos educandos, para que eles memorizem, repitam, guardem e arquivem. Funciona, ainda, como um modelo disciplinar, que pretende docilizar os corpos, tornando-os mais obedientes. O autor argumenta que a nossa realidade como um todo é domesticadora, mas afirma

ciona eleição de diretores de colégios públicos, após ocupações. G1, Rio de Janeiro, 06 jun. 2016. Disponível em: <http://glo.bo/1Y35Fn6>. Acesso em: 19 maio 2020.

70 SAERJ era uma avaliação obrigatória que, segundo os estudantes, não considerava as especificidades de cada unidade escolar e era baseada na meritocracia. O fim dessa avaliação foi uma das conquistas dos estudantes com as ocupações.

8 Os estudantes secundaristas de São Paulo tiveram acesso a essa mobilização a partir do filme documentário A Rebelião dos Pinguins, de Carlos Prozanato (2007).

9 Os estudantes secundaristas de São Paulo tiveram acesso a essa mobilização a partir do filme documentário A Rebelião dos Pinguins, de Carlos Prozanato (2007). 
que é possível libertar-se dessa força através da práxis, entendida como "ação e reflexão dos homens sobre o mundo para transformá-lo" (FREIRE, 2013, p. 52).

Entende-se, então, que o gesto de ocupar uma escola pode ser considerado uma maneira de romper com essa lógica domesticadora da qual fala Paulo Freire (2013). Os secundaristas rompem e logo experimentam a escola como um lugar de criação de outra realidade: a realidade idealizada por eles. John Holloway (2013), no livro Fissurar o capitalismo, argumenta sobre a importância do não, de romper com a lógica do capital através das fissuras desse sistema e acrescenta que a força do não mais servir aumenta quando se procuram outras formas de viver, quando se propõe "uma atividade que não é condicionada pela regra do dinheiro, que não é condicionada pelas regras do poder" (HOLLOWAY, 2013, p. 7). Ele acredita, portanto, em um movimento de negação-e-criação dentro da lógica capitalista. A partir dessa perspectiva, é possível perceber a ocupação como uma forma de fissura, por negar a antiga estrutura formal de educação e propor uma outra forma de pensar e agir sobre a escola e, consequentemente, sobre a realidade social como um todo.

Tim Prentki acredita que em nosso século vivemos a dominância do modelo neoliberal da globalização, que é a única e totalizante supernarrativa do capitalismo corrente. Como resposta, ele busca desenvolver a ideia de narrativas alternativas.

Assim, uma narrativa é aquela na qual as relações são formadas na base da dignidade, e não do dinheiro. É a narrativa que tem como objetivo a criatividade e a imaginação; é, portanto, uma narrativa em que a arte tem um papel importante. Não me refiro, no entanto, à narrativa da satisfação pessoal através do afastamento das injustiças do mundo, mas de um processo de satisfação social através da autodeterminação de agrupamentos formados por relações horizontais, e não verticais. (PRENTKI, 2008, p. 20).

A escola ressignificada, na qual os estudantes puderam organizar as atividades de acordo com os seus interesses, conviver 
diariamente com o outro e com o outro tomar decisões sobre o espaço, engajar-se na luta por melhorias na educação, descobrir um novo sentido para aquele lugar e cuidar dele como os verdadeiros donos, não poderia ser entendida como uma narrativa alternativa? Não seria uma espécie de fissura do capitalismo? Não seria a própria ideia de humanização ${ }^{10}$ dos indivíduos que não pretendem continuar imersos em uma realidade domesticadora e querem transformar o mundo se percebendo e agindo como sujeitos de suas próprias histórias?

Em uma entrevista publicada no artigo As ocupações das escolas estaduais da região de Sorocaba/SP: falam os estudantes secundaristas, o estudante com o codinome Marighella ${ }^{11}$, de São Paulo, a respeito do amor que tem pela escola e sobre as ocupações de 2015, afirma que o motivo de ter ocupado

[...] foi justamente o amor que eu tenho pela minha escola e o fato de eu me colocar no lugar das outras pessoas que estavam lutando para que isso acontecesse, para que o amor pela escola permanecesse... e o desejo de continuar lá e de criar e contar uma história dentro da escola. (MARTINS; TARDELLI; PEREIRA; SANTOS, 2016, p. 233).

Após analisar cinco escolas da Rede Estadual do Rio de Janeiro, os pesquisadores Andrea Doyle e Arthur Bezerra (2016) acrescentam reflexões acerca do espaço ocupado e de que maneira essa ação é uma forma de mostrar, além do amor, o pertencimento àquele espaço.

As ocupações fazem isso: pela ação política de ocupar, os estudantes se tornam sujeitos, entendem que aquele espaço é deles, se tornam responsáveis por aquele processo e exigem ser ou-

10 Segundo Paulo Freire (2013) a humanização é vocação dos homens, que é negada "na injustiça, na exploração, na opressão, na violência dos opressores. Mas afirmada no anseio de liberdade de justiça, de luta dos oprimidos, pela recuperação de sua humanidade roubada" (FREIRE, 2013, p.40). Por isso, a desumanização, apesar de um fato histórico, não seria um destino dado.

11 Os pesquisadores desse artigo consideraram importante manter em sigilo as identidades dos estudantes, que sugeriram seus codinomes. 
vidos e poder opinar nas decisões que os afetam diretamente. Ocupam porque reivindicam mais qualidade no ensino, maior compreensão do mundo, mais acesso à informação. E o mais interessante é que fazem tudo isso ao mesmo tempo, de forma horizontal, se divertindo e se desentendendo, trabalhando e aprendendo, resistindo e dialogando. (DOYLE; BEZERRA, 2016, p. 202).

Nesse sentido, o gesto de ocupar, que é preenchido de afeto pelo espaço e pelos que ocupam, e preenchido pelo interesse em explorar de outras maneiras as narrativas que preenchem 0 universo da escola, pode ser entendido como uma fissura que, aos poucos, vai roendo as estruturas e encontra novos significados dentro daquele ambiente. A escola, portanto, passa a fazer sentido para os que acreditam nela como lugar de pensar e vivenciar tanto as individualidades quanto as coletividades de maneira horizontal e dialógica.

\section{TEATRO E OCUPAÇÃO}

Assim que ocuparam o espaço escolar, os estudantes passaram a se organizar em comissões específicas, que cuidavam, por exemplo, da limpeza, cozinha, segurança, comunicação e atividades culturais. Em Angra dos Reis, os secundaristas tiveram acesso a um manual, escrito por estudantes da Argentina e do Chile, traduzido e adaptado pelo Coletivo O Mal Educado ${ }^{12}$

12 No livro Escolas de Luta (2016), os pesquisadores esclarecem que o Coletivo O Mal Educado teria surgido através da rede de contatos que o Movimento Passe Livre - São Paulo gerou entre os estudantes que já tinham se mobilizado tanto em 2009 contra uma diretora de escola no bairro Rio Bonito, quanto em 2011 a partir da experiência da Poligremia, que foi a articulação entre grêmios desenvolvida durante os anos de 2010 e 2011 . Esse manual foi um dos suportes utilizados inicialmente pelos secundaristas de São Paulo em 2015 e, no ano seguinte, pelos estudantes do Rio de Janeiro. O Coletivo Mal Educado disponibilizou em seu site Facebook esse manual e outras informações a respeito da organização. O MAL-EDUCADO. Como ocupar um colégio?: manual escrito por estudantes secundaristas da Argentina e Chile. 2015. Disponível em: <https://gremiolivre.files. wordpress.com/2015/10/como-ocupar-um-colc3a9gio.pdf>. Acesso em: 29 de julho de 2019. 
de São Paulo, que teria como objetivo facilitar o caminho para os que estavam iniciando seus processos de luta. Nele existe a sugestão da divisão da ocupação nessas comissões básicas e uma delas é a comissão de atividades. O Mal Educado (2015) recomenda que elas sejam realizadas durante todo o dia e contem com a participação de todos, inclusive os que são apoiadores da ocupação. Diz ainda que essas atividades podem ser recreativas e baseadas em um tema de interesse do grupo.

Quais papéis, então, as artes, especificamente o teatro, poderiam desempenhar nesse espaço? Na explicação introdutória do livro Teatro do Oprimido e outras poéticas políticas, Augusto Boal (2010) diz que o teatro é uma arma muito eficiente, que pode servir tanto para dominar os sujeitos, sendo apropriado constantemente pelas classes dominantes, como para ser uma arma para a libertação. Boal (2009) também argumenta em Estética do Oprimido que os canais estéticos da Palavra (que estariam ligados ao pensamento simbólico), da Imagem e do Som (pensamentos sensíveis) são latifúndios das classes dominantes e, portanto, suas ideias penetram nos cérebros dos oprimidos através deles. Assim, ele acredita que os opressores começam a dominar por esses canais antes de oprimirem por meio do dinheiro e das armas.

Analisando alguns relatos e as primeiras entrevistas feitas com estudantes de Angra dos Reis, pude perceber que é possível pensar em inúmeros papéis para as artes nesse contexto: um lugar de alívio de tensões; um momento para aprofundar temas fundamentais na luta dos secundaristas, como sugere o manual do Mal Educado (2015); um espaço de sensibilização do corpo e da mente individual e coletiva; um momento para entender o mundo a partir de outras formas estéticas; ou então tudo isso em um mesmo encontro.

É importante, entretanto, ressaltar que o teatro por si só já é a forma e o conteúdo. E, por isso, o meu objetivo com esse estudo não é entender as potencialidades específicas do teatro, mas perceber de que maneiras essa linguagem dentro de um espaço escolar ocupado pode dialogar com as necessidades dos indivíduos ali inseridos e interessados nessa prática. Busco en- 
tender como os sujeitos que querem transformar a realidade podem transformar também Palavra, Imagem e Som em armas para a libertação. Edith Scher (2015), ao analisar o teatro comunitário argentino, entende o teatro como uma prática transformadora por si. No entanto, existe o perigo de se desenvolver um teatro que mantém as coisas como estão, dando continuidade à estética anestésica dos opressores, que para Boal (2009) esteriliza e programa os cérebros dos oprimidos na obediência, no mimetismo e na falta de criatividade. Entendo, porém, que essa estética não dialoga com a proposta de luta dos secundaristas, assim como com a prática do teatro nos contextos comunitários.

Em 2018 pude iniciar as entrevistas da pesquisa e o estudante Marlon Gomes, que atualmente estuda pedagogia na Universidade Federal Fluminense, UFF, relembrou as atividades de teatro propostas pelo professor e artista de Angra dos Reis Felipe Santana, que esteve com eles durante parte considerável da ocupação no CIEP 302.

O que mais teve foi teatro, porque a galera estava toda pilhada, cabeça a mil... eu lembro que a Ingret D'ávila ${ }^{13}$ falava: a gente precisa fazer alguma coisa, se não o pessoal vai endoidar. Tinha muita dinâmica. Quando começou, os outros falavam "não vou fazer teatro, não quero ser ator". Até o Felipe chegar e falar "gente, vai ser legal". Começou com pouca gente, mas terminava e todos esperavam a hora de fazer de novo. Tem uma atividade dele que eu não esqueço. Estava todo mundo muito nervoso, muito nervoso, ele botou todo mundo de frente um para o outro, um olhando para a cara do outro. Estava todo mundo sério, porque tinha brigado entre si. Ele falava "não para de olhar". Depois ele falou "tá, pode parar", então todo mundo começou a rir. Riu, riu. "Pronto, acabou, é isso. Vocês precisavam se olhar". Estava todo mundo preocupado e ninguém olhava mais para o outro. Aquele dia foi muito bom. A gente riu demais ${ }^{14}$.

13 Outra estudante entrevistada durante a pesquisa e que esteve presente nas ocupações.

14 Em entrevista pessoal em 05/05/2018. 
A estudante de Sorocaba, que na pesquisa dos autores Marcos Martins, Fábio Filho, Keyla Pereira e Érico dos Santos tem como codinome Luna, também fala da importância desses momentos para as ocupações.

\begin{abstract}
Teve uma roda de conversa de história, uma moça foi contar história pra gente, história de criança mesmo, sabe? Recitar versos mesmo. Pegar lá o: “Batatinha quando nasce se esparrama pelo chão" e coisa assim, só que envolveu a gente. A gente ficou girando igual palhaço no pátio, só que aquilo estava envolvendo, entendeu? A gente queria aquilo, e isso era o mais importante, era trazer um ambiente de cultura e de interesse dos alunos e não só porque "tem que tá no currículo do professor" ou "tem que tá no currículo do aluno", mas não porque aquilo não interessa de fato pros alunos, entendeu? Então era mais ou menos isso. (MARTINS; TARDELLI; PEREIRA; SANTOS, 2016, p. 247).
\end{abstract}

No livro Escolas de Luta, os pesquisadores Antonia Campos, Jonas Medeiros e Márcio Ribeiro (2016) argumentam que essas e tantas outras atividades culturais romperam com o individualismo escolar pré-ocupação e mostraram que a experiência escolar pode ser "uma coisa prazerosa e que valorize e reconheça os estudantes enquanto sujeitos e seres humanos" (CAMPOS; MEDEIROS; RIBEIRO, 2016, p. 151).

É, então, importante entender a ocupação e a luta dos estudantes, que teve caráter horizontal, autônomo, coletivo, baseado na escuta e no afeto pelo outro e pela escola, como um lugar de transformação e construção de uma "escola dos sonhos" na busca por um mundo melhor, como argumenta a estudante de Angra dos Reis, Yana dos Santos ${ }^{15}$. Nesse lugar de transformação, tendo a arte um papel importante, é preciso que como pesquisadores da linguagem do teatro possamos refletir de que maneiras podemos dialogar a nossa arte/arma com a narrativa alternativa que os estudantes deram à escola. Soma-se a esse pensamento a ideia de Boal:

15 Em entrevista pessoal em 04/05/2018. 
O pensamento sensível, que produz arte e cultura, é essencial para a libertação dos oprimidos, amplia e aprofunda sua capacidade de conhecer. Só com cidadãos que, por todos os meios simbólicos (palavras) e sensíveis (som e imagem), se tornam conscientes da realidade em que vivem e das formas possíveis de transformá-la, só assim surgirá, um dia, uma real democracia. (BOAL, 2009, p. 16).

Considerei, nesse sentido, que para pensar o teatro dentro das ocupações seria necessário dialogar com as bases do campo de pesquisa Teatro e Comunidade, que tem ligação com as ideias de Augusto Boal e Paulo Freire, visto que ambos buscam um teatro e uma pedagogia baseada na reflexão sobre a realidade em prol de uma transformação social. Elaborei, assim, encontros onde explorei jogos do Teatro do Oprimido e dialoguei com os estudantes sobre as maneiras pelas quais o teatro, naquele momento, poderia contribuir para a luta. Percebi que em outras ocupações não apenas o Teatro do Oprimido foi utilizado e cheguei à conclusão de que essa metodologia era um caminho possível, mas não único.

\section{OCUPAÇÃO EM DIÁLOGO COM O CAMPO DE PESQUISA TEATRO E COMUNIDADE}

As práticas do campo Teatro e Comunidade têm em comum um trabalho baseado na horizontalidade, na busca pela autonomia dos sujeitos, na construção coletiva, nas relações de afeto e amor por si e pelo próximo; e, consequentemente, na transformação do mundo. Segundo Marcia Pompeo (2015), os métodos desenvolvidos no Teatro e Comunidade propõem um trabalho de baixo para cima, ou de dentro para fora, como preferir cada contexto específico. A autora mostra que no desenvolvimento desses métodos

[...] existe a certeza da necessidade de respeito ao conhecimento do povo, de que desenvolvimento não pode ser construído sem um diálogo honesto envolvendo sujeitos aprendendo uns com 
os outros, respeitando o conhecimento um do outro, e trabaIhando juntos para entenderem e resolverem seus problemas. (NOGUEIRA, 2015, p. 115).

Tim Prentki acrescenta que esse tipo de teatro é mais necessário do que nunca, visto que é "uma atividade coletiva em um mundo onde a maior parte da população leva vidas de isolamento e fragmentação crescentes" (PRENTKI, 2008, p. 31). Acrescenta, ainda, que o teatro "reafirma os humanos como seres sociais cuja criatividade e imaginação são estimuladas pela experiência de trabalhar juntos" (PRENTKI, 2008, p. 33).

Quando comecei a planejar as oficinas de teatro desenvolvidas com os estudantes de Angra dos Reis, no CIEP 302 Charles Dickens, e depois com estudantes de duas escolas na Zona Oeste do Rio de Janeiro, o C.E. Salim Miguel e o C.E. Stuart Edgar Angel Jones, as propostas de uma pedagogia libertadora e de um teatro no qual todos poderiam ser atores logo apareceram como um possível caminho de trabalho.

As oficinas que desenvolvi foram divididas em três momentos. O primeiro foi uma conversa inicial, por meio da qual busquei entender em um breve diálogo o que os estudantes pretendiam com aquele encontro e de que forma eu poderia me inserir naquele contexto. Em um segundo momento, levei alguns jogos e exercícios, sendo a maioria do Teatro do Oprimido, que trabaIhavam, sobretudo, o Teatro-Imagem. Por fim, no terceiro momento, construímos improvisações teatrais que geraram uma conversa no fim de cada oficina. No CIEP 302 e no C.E. Stuart Angel, não somente estudantes, mas também professores fizeram parte da oficina, já no C.E. Salim Miguel apenas os estudantes participaram ${ }^{16}$. Os encontros tiveram em média três a quatro

16 É importante ressaltar que essa proposta foi a que pensei antes de chegar no encontro. No entanto, depois do acordo inicial com os estudantes, que disseram que gostariam de fazer teatro para descontrair e também falar sobre diversas opressões que se relacionavam com temas como: ser mulher, a questão LGBTQI+, negritude, relação entre alunos, professores e diretores; percebi que poderia manter a mesma estrutura. Não houve, portanto, modificação no planejamento, apenas no tempo em que duraram os jogos e os debates surgidos 
horas com cerca de quinze participantes.

Apesar de começar a planejar encontros teatrais que fossem maleáveis, tinha consciência de que ter como base os jogos e exercícios de Imagem, Som ou Palavra, como sugere a metodologia do Teatro do Oprimido, seria um caminho com possibilidades mais positivas que negativas. No entanto, mais do que trabalhar de maneira prática os jogos e exercícios do autor, considerei que seria essencial não esquecer o caráter ideológico de sua proposta e de outros pesquisadores que dialogam com seus ideais. Nesse sentido, encontrei semelhanças entre as práticas pedagógicas e teatrais desenvolvidas por autores como Augusto Boal e Paulo Freire que permeiam o campo do Teatro e Comunidade e as práticas desenvolvidas pelos e com os estudantes dentro das ocupações secundaristas.

É fundamental, no entanto, pensar que as práticas teatrais comunitárias têm uma característica importante: o trabaIho continuado. Por esse motivo, inicialmente, considerei que não seria possível pensar nesse diálogo, já que não sabíamos quanto tempo as ocupações durariam ${ }^{17}$. No entanto, ainda que fosse por um tempo curto, percebi que era possível desenvolver uma prática continuada em acordo com os estudantes, podendo durar dias, semanas ou alguns meses, dependendo do diálogo estabelecido e da condição de cada espaço ocupado. O importante, nesse caso, era construir, a partir de acordos estabelecidos conjuntamente, trocas horizontais e formas coletivas de pensar e experimentar através do teatro a transformação de si e do mundo.

a partir deles, visto que cada lugar ressaltou uma luta que era mais urgente de acordo com as aberturas que os jogos davam. No C.E. Salim Miguel, por exemplo, a questão do uniforme e do julgamento sobre as roupas que as meninas usavam foi um dos pontos dialogados. No C.E. Stuart Angel, os estudantes e professores que participaram colocaram em cena questões mais diretas à escola e às opressões que surgiam quando as pessoas não acreditavam na luta deles.

17 No Rio de Janeiro, as ocupações iniciaram no fim de março de 2016. Os estudantes começaram a desocupar suas escolas por volta do fim de maio do mesmo ano. 
Edith Scher (2015), refletindo sobre as práticas comunitárias do teatro desenvolvido na Argentina, também aponta outra questão fundamental a respeito do Teatro e Comunidade, que provocou minhas reflexões a respeito das práticas desenvolvidas nas ocupações:

Quando falamos de arte e transformação social no quadro do teatro comunitário no nosso país, não nos referimos de uma forma idealista nem a uma ação direta sobre as estruturas econômicas e políticas, nem, em sentido contrário, à convicção de mudar exclusivamente os indivíduos. O que quer isto dizer? Por um lado, que não falamos apenas de uma transformação individual, ou seja, de um crescimento pessoal expressivo, como aquele a que se aspira quando assistimos a aulas de uma disciplina artística. Evidentemente, o teatro comunitário implicará um desenvolvimento expressivo pessoal também, mas que não se conquista pela via tradicional. Por outro lado, o teatro comunitário não alimenta a ingênua conviç̧ão de que pode modificar de forma direta as políticas, a distribuição orçamental, a injustiça social. Todavia, é uma prática que incide, lenta e profundamente, nos sistemas de crenças, naquilo que parece imutável e que, contudo, se pode alterar. É que a arte é [...] um formidável amplificador do horizonte humano, porquanto permite e habilita pensar fora dos limites. (SCHER, 2015, p. 94).

A partir dessa perspectiva, penso que a prática artística dentro do contexto de ocupação não pareceu ou pretendeu ter como responsabilidade mudar a sociedade imediatamente. Não entendo como possível colocar o teatro (e apenas ele) à frente de uma mudança social mais ampla; e, sim, à frente de micro revoluções individuais e coletivas. Essas, sim, podem contribuir para transformações a longo prazo.

\section{CONSIDERAÇÕES FINAIS}

Camaradagem, dignidade, amorosidade, solidariedade, fraternidade, amizade, ética: todos esses nomes contrastam com as relações mercantilizadas, monetizadas do capitalismo, todos 
descrevem como antecipação ou criação de uma sociedade para além do capitalismo. (HOLLOWAY, 2013, p. 45).

Concluir este texto é um desafio, visto que a pesquisa se encontra em estágio de desenvolvimento e, à medida que descubro novos autores e desenvolvo mais entrevistas, novas perspectivas se abrem a respeito das mobilizações secundaristas de 2016. No entanto, uma coisa é certa: quando o tema é ocupação, rapidamente palavras como horizontalidade, coletividade, afeto, escuta e atividades são associadas.

Nesse sentido, é possível entender que a abertura dos secundaristas à experimentação de práticas artísticas dentro das ocupações possibilitou o desenvolvimento de diversas linguagens dentro daquele espaço. É claro que, dentro desse processo de experimentação artístico-pedagógico, não se pode garantir que todas as atividades sejam desenvolvidas como prática transformadora. Estávamos todos aprendendo. Juntos. E nessa vivência corre-se o risco, muitas vezes de repercutir a estética anestésica apontada por Augusto Boal (2009). Ainda assim, pode-se dizer que práticas e metodologias teatrais que buscam a transformação do mundo, do sujeito e que possibilitam que os indivíduos nomeiem o mundo a partir de suas perspectivas têm um diálogo próximo com a tática de luta optada pelos secundaristas do Rio de Janeiro e, por isso, a importância de se ter como base dentro dos espaços ocupados metodologias desenvolvidas dentro do vasto campo de pesquisa Teatro e Comunidade, certamente adaptáveis à realidade da ocupação. 


\section{REFERÊNCIAS}

BARAÚNA, Tânia. Considerações sobre a pedagogia do oprimido de Paulo Freire e a Metodologia do Oprimido de Augusto Boal. LIGIERO, Zeca. TURLE, Licko e ANDRADE, Carla de. (Org.). In: Augusto Boal: arte, pedagogia e política. Rio de Janeiro: Mauad X, 2013. p. 187-206.

BARREIRA, Gabriel. RJ sanciona eleição de diretores de colégios públicos, após ocupações. G1, Rio de Janeiro, 06 jun. 2016. Disponível em: <http://glo.bo/1Y35Fn6>. Acesso em: 19 maio 2020.

BOURDIEU, Pierre. A economia das trocas simbólicas. $5^{\text {a }}$ ed. São Paulo: Perspectiva, 2007.

DOYLE, Andréa; BEZERRA, Arthur. (In)formação e cultura nas escolas ocupadas do Rio de Janeiro. Pesquisa Brasileira em Ciência da Informação e Biblioteconomia, v. 11, p. 194-203, 2016.

BOAL, Augusto. A Estética do Oprimido. Rio de Janeiro: Garamond, 2009.

. Teatro do Oprimido e outras Poéticas Políticas. 10. ed. Rio de Janeiro: Civilização Brasileira, 2010.

BONI, Valdete; QUARESMA, Silvia Jurema Leone. Aprendendo a entrevistar: como fazer entrevistas em Ciências Sociais. Revista Eletrônica dos Pós-Graduandos em Sociologia Política da UFSC, Santa Catarina, v. 2. n. 1, p. 68-80, jan/jul, 2005.

CAMPOS, Antonia J. M.; MEDEIROS, Jonas; RIBEIRO; Márcio M. Escolas de luta. São Paulo: Veneta, 2016.

COUTINHO, Marina Henriques. A favela como palco e personagem. Rio de Janeiro: DP et Alii, FAPERJ, 2012. 
ERVEN, Van Eugene. Artes comunitárias: origens e presença no mundo. In: CRUZ, Hugo (org.). Arte e Comunidade. Lisboa: Fundação Calouste Gulbenkian, 2015. p. 61-83.

FREIRE, Paulo. Pedagogia do Oprimido. 54. Ed. - Rio de Janeiro: Paz e Terra, 2013.

MARTINS, Marcos Francisco; TARDELLI FILHO, Fábio Alexandre; PEREIRA, Keyla; SANTOS, Érico. As ocupações das escolas estaduais da região de Sorocaba/SP: falam os estudantes secundaristas - Entrevista. Crítica Educativa. v. 2, n. 1, p. 227260, jan./jun. 2016.

HOLLOWAY, John. Fissurar o capitalismo. São Paulo: Publisher, 2013.

MOCARZEL, Marcelo; ACCETTA ROJAS, Angelina; RANGEL, Mary. \#OCUPAIEPIC: representações culturais da juventude na ocupação de uma escola estadual em Niterói-RJ. EDUCAÇÃo ON-LINE (PUCRJ), v. 25, p. 19-39, 2017.

NOGUEIRA, Márcia Pompeo. Ventoforte: no teatro em comunidades. Florianópolis: Letras Contemporâneas, 2015.

O MAL-EDUCADO. Como ocupar um colégio?: manual escrito por estudantes secundaristas da Argentina e Chile. 2015. Disponível em: <https://gremiolivre.files.wordpress.com/2015/10/comoocupar-um-colc3a9gio.pdf>. Acesso em: 29 de julho 2019.

PINHEIRO, Diógenes. Escolas ocupadas no Rio de Janeiro em 2016: motivações e cotidiano. Iluminuras, Porto Alegre, v. 18, n. 44, p. 265-283, jan/jul, 2017.

PRENTKI, Tim. Contranarrativa. Ser ou não ser: Esta não é a questão. In: NOGUEIRA, Marcia Pompeo (org.). Teatro na comunidade, interações, dilemas e possibilidades. Florianópolis: Ed. UDESC, 2009. p. 13-36. 
PROZANATO, Carlos. A Rebelião dos Pinguins. 2016. Disponível em: <https://www.youtube.com/watch?v=kYzkDql56yw>. Acesso em: 21 de fev. 2020.

SCHER, Edith. Teatro comunitário argentino: 1983-2014. In: CRUZ. Hugo (org.). Arte e Comunidade. Lisboa: Fundação Calouste Gulbenkian, 2015. p 83-99. 